\title{
Policy and prevention efforts for gaming should consider a broad perspective
}

\author{
Commentary on: Policy responses to problematic video game use: A systematic \\ review of current measures and future possibilities (Király et al., 2018)
}

\author{
NANCY M. PETRY ${ }^{1 \dagger}$, KRISTYN ZAJAC $^{1 *}$, MEREDITH GINLEY $^{1}$, JEROEN LEMMENS $^{2}$, HANS-JÜRGEN RUMPF ${ }^{3}$, \\ CHIH-HUNG $\mathrm{KO}^{4}$ and FLORIAN REHBEIN ${ }^{5}$
}

\author{
${ }^{1}$ Calhoun Cardiology Center, University of Connecticut School of Medicine, Farmington, CT, USA \\ ${ }^{2}$ Faculty of Social and Behavioural Sciences, University of Amsterdam, Amsterdam, The Netherlands \\ ${ }^{3}$ Department of Psychiatry and Psychotherapy, University of Lübeck, Lubeck, Germany \\ ${ }^{4}$ Department of Psychiatry, Kaohsiung Medical University Hospital, Kaohsiung, Taiwan \\ ${ }^{5}$ Criminological Research Institute of Lower Saxony, Hannover, Germany
}

(Received: February 6, 2018; revised manuscript received: July 3, 2018; accepted: July 12, 2018)

\begin{abstract}
Internet gaming disorder is gaining attention around the world. Some efforts have been directed toward preventing gaming problems from developing or persisting, but few approaches have been empirically evaluated. No known effective prevention intervention exists. Reviewing the broader field of prevention research should help research and best practices move forward in abating problems that arise from excessive gaming.
\end{abstract}

Keywords: Internet gaming disorder, prevention, public policy

With the inclusion of Internet gaming disorder (IGD; Petry \& O'Brien, 2013) in the fifth edition of Diagnostic and Statistical Manual of Mental Disorders (American Psychiatric Association, 2013), along with a similar proposal for introducing gaming disorder in the International Classification of Diseases - version 11, interest in gaming problems has increased from scientific, clinical, and public health perspectives. Research and clinical understanding of IGD, however, remains in its early stages (Petry, Rehbein, Ko, \& O'Brien, 2015). Multiple perspectives exist on the nature and context of the condition and its constellation of symptoms. Nevertheless, emerging clinical, epidemiological, and public health data indicate that excessive gaming can be problematic in a minority of gamers (e.g., Wittek et al., 2016), with higher prevalence in young age groups (Rehbein, Kliem, Baier, Mößle, \& Petry, 2015).

Király et al. (2018) describe efforts implemented around the world with the intent of reducing harms associated with gaming. Their paper synthesizes the limited literature in this area and should bring awareness to prevention work.

Consideration of the wider literature of prevention research in medicine, mental health, and addictive disorders is relevant to IGD. Broad review of public health issues can facilitate efforts for emerging areas and may more rapidly advance an understanding of methods to minimize problems with gaming. The fields of alcohol, tobacco, substance use, and gambling are perhaps most directly relevant. Many of these behaviors are legal, similar to gaming. Furthermore, for most if not all of these behaviors, occasional use or engagement does not necessarily translate to harms, in the same manner that occasional game play is clearly not problematic. Substance use and gambling behaviors are common in youth and young adults (Welte, Barnes, Tidwell, \& Hoffman, 2011), as is gaming (Rehbein et al., 2015; Wittek et al., 2016).

The addictive disorder field has struggled to develop effective prevention interventions (Ennett, Tobler, Ringwalt, \& Flewelling, 1994) and, only after decades of research, has uncovered strategies with modest effects on substance use (Toumbourou et al., 2007). Thus, it is not surprising that effective prevention strategies do not exist for IGD, a much less established or understood condition. Reviewing prevention efforts for substance use and gambling disorders, as well as prevention interventions broadly, may guide future efforts for gaming prevention. While other taxonomies are also used (e.g., universal, selective, and indicated prevention), this examination applies the historical terms of primary, secondary, and tertiary preventions. Regardless of terminology, this overview may help in evaluating how other experiences can apply to the field of IGD.

Primary prevention aims to prevent problems or diseases before they manifest. Typically, primary prevention efforts relate to reducing or eliminating exposures to hazardous

\footnotetext{
${ }^{\dagger}$ Deceased.

* Corresponding author: Kristyn Zajac, PhD; Assistant Professor of Medicine, Calhoun Cardiology Center, University of Connecticut School of Medicine, MC3944, 263 Farmington Avenue, Farmington, CT 06030, USA; Phone: +1 860679 8572; Fax: +1 860679 1312; E-mail: zajac@uchc.edu
}

This is an open-access article distributed under the terms of the Creative Commons Attribution-NonCommercial 4.0 International License, which permits unrestricted use, distribution, and reproduction in any medium for non-commercial purposes, provided the original author and source are credited, a link to the CC License is provided, and changes - if any - are indicated. 
situations or behaviors. Examples include legislation - and enforcement of legislation - to ban or control the use of hazardous products (e.g., asbestos and lead paint) or to mandate safety and health behaviors (e.g., use of seat belts and helmets), and education about healthy and safe habits (e.g., eating well, exercising regularly, and not smoking). Immunizations are another example of primary prevention efforts aimed at the contraction of measles, mumps, and other infectious diseases. Governments legislate some primary prevention efforts to enact widespread, and ideally universal, implementation, but typically such regulations only occur after data establish associations between the precursor (e.g., environmental toxin, infection, and accidents) and adverse outcome (e.g., disease state and likelihood of brain damage).

Primary prevention efforts that have been governmentally mandated and enforced are (or at least one can argue should be) efficacious. Required use of seat belts in cars has clearly reduced accident-related morbidity and mortality (Williams \& Lund, 1986), and legislation raising the legal age of alcohol consumption from 18 to 21 years in the US (where adolescents as young as 14-16 years old drive) resulted in reductions in alcohol-related motor vehicle accidents (Du Mouchel, Williams, \& Zador, 1987). Immunizations have nearly eradicated some formally common childhood illnesses.

In the case of addictions or mental health disorders, no immunizations exist. For educational efforts and anti-use advertising (e.g., "This is your brain on drugs"), relatively little is known about effectiveness. The widespread Drug Abuse Resistance Education campaign in the US is actually not useful in reducing drug use (Ennett et al., 1994). Nevertheless, these types of education and advertising campaigns do not cause any known harms, and educational and anti-use advertising campaigns occur even in the absence of data on their utility. Government and professional agencies, such as Ministry of Health and Welfare in Taiwan and American Academy of Pediatrics in the US, for example, provide guidelines and educational materials about the use of electronics and gaming.

Advertising and educational primary prevention efforts target a wide group of individuals. Hence, it is difficult to establish their ability to reduce harms for low base rate conditions. For example, decreasing the incidence of gambling disorder, a condition that occurs in only $0.4 \%$ of the population (Petry, Stinson, \& Grant, 2005), requires the study of several thousands of individuals. For decades, the gambling field has attempted to identify efficacious primary prevention efforts, but debate persists about their efficacy and effectiveness, and none are widely implemented (Ginley, Whelan, Pfund, Peter, \& Meyers, 2017).

Given this context, it is not surprising that effective primary prevention efforts for IGD, a newer disorder with a prevalence rate of about 1\% (Petry, Zajac, \& Ginley, 2018), remain elusive. Educational and awareness efforts, such as rating systems on games and parental controls, may be perceived as forms of primary prevention. Governments do not legally mandate warning or rating systems in most (if not all) countries, and one could argue that they should not because data regarding their efficacy and effectiveness are lacking. Furthermore, such efforts may be counterproductive as persons, especially children, may be drawn to games labeled for mature or adult audiences only. The utility of parental controls to decrease gaming problems may be hindered, because it is largely incumbent on parents to apply these systems. Unfortunately, the parents who most probably need to prevent gaming problems in their children may be the least likely to familiarize themselves with and use these systems (Carlson et al., 2010; see also Gentile, in press).

Considering primary prevention literature more broadly may provide insight toward next steps in primary prevention research for gaming. Evaluations of primary prevention interventions are most efficiently conducted in subgroups likely to develop problems. For gaming, these include highrisk male youth (Petry et al., 2015; Rehbein et al., 2015) and those with mental health risk factors, such as attentiondeficit hyperactivity disorder (ADHD), depression, and anxiety (Desai, Krishnan-Sarin, Cavallo, \& Potenza, 2010; Gentile et al., 2011; Petry et al., 2018; van Rooij et al., 2014). Primary prevention efforts aimed at parents of such children may demonstrate whether existing or new approaches reduce the onset of harms in high-risk children. In contrast, directing efforts toward all game players will likely yield less robust effects, as only a small proportion will go on to experience problems (Müller et al., 2015; Rehbein et al., 2015; van Rooij, Schoenmakers, Vermulst, van den Eijnden, \& van de Mheen, 2011; Wittek et al., 2016). Aiming minimal educational or advertising primary prevention interventions at gamers who already have significant problems (or their parents) will also probably not be useful, as these individuals likely require more intensive treatments. The substance use and mental health literature clearly indicate that more comprehensive approaches are needed to enact behavioral changes in persons who have already developed significant problems relative to those with minimal difficulties (US Department of Health and Human Services, 2016).

Ultimately, more prescriptive primary prevention methods may be useful. Elimination of the ability to play online games during school or sleeping hours or for time periods that exceed certain durations eventually may prove to reduce incidence rates of gaming problems. However, in the absence of solid data, opponents to these types of mandates can, and likely will, argue against them.

Secondary prevention decreases the impact of a disease or injury that has already occurred. It includes efforts to detect and treat disease or injury as soon as possible to halt or slow impairment, strategies to prevent problems from reemerging, and programs that return persons to their predisease or injury state. Examples include screenings to detect disease in early stages (e.g., mammograms to detect breast cancer) and interventions to prevent additional disease or injuries (e.g., low-dose aspirin for stroke).

Clearly, secondary prevention efforts can be effective and even cost-effective, with insurers and public health initiatives covering their costs. However, designing and evaluating secondary prevention efforts require solid understanding of the risk factors and course of the condition as well as consensus on how to assess the condition reliably and accurately. Research has identified risk factors for gaming problems (Gentile et al., 2011; Lemmens, Valkenburg, \& Peter, 2011; Petry et al., 2018; Rehbein \& Baier, 2013), but its clinical assessment and course remain elusive 
(Petry et al., 2014, 2018). Excessive Internet use in any format or for a variety of functions is often confounded with excessive or problematic gaming, despite growing evidence of their differences (Király et al., 2014; Montag et al., 2015; Rehbein \& Mößle, 2013; Siomos, Dafouli, Braimiotis, Mouzas, \& Angelopoulos, 2008; van Rooij, Schoenmakers, van de Eijnden, \& van de Mheen, 2010). Assessing multifaceted harms increases heterogeneity, rendering detection of changes even more difficult. Furthermore, at least some data suggest that gaming problems dissipate on their own in persons with problems (Gentile et al., 2011; Rothmund, Klimmt, \& Gollwitzer, 2016; Scharkow, Festl, \& Quandt, 2014; Thege, Woodin, Hodgins, \& Williams, 2015; van Rooij et al., 2011). Therefore, establishing benefits of secondary prevention efforts will be all the more challenging, because any intervention will need to demonstrate improvements in subsiding symptoms more quickly and/or for longer time periods beyond natural recovery rates.

Existing prevention efforts include attempts to apply gaming shutdown and fatigue systems, which may be considered primary prevention efforts, if they impact all gamers, or secondary prevention assuming that their impact applies most directly toward those who have already begun developing some gaming-related problems. Few studies have evaluated the efforts empirically, and they require substantial and sophisticated technology. Limiting sales of addictive substances, or gambling, similarly requires substantive efforts and constant monitoring (e.g., of retail outlets and at casinos).

Secondary prevention efforts efficacious in other contexts include screening and brief intervention initiatives, such as those for gambling, alcohol use, and substance-use disorders (Madras et al., 2009; Neighbors et al., 2015). Evaluation of these approaches is most efficient in high-risk groups, such as youth or young adults with other frequently co-occurring mental disorders with some, but not necessarily full-blown, IGD symptoms. Very few such efforts are ongoing in the context of minimizing early subthreshold gaming problems (King, Delfabbro, Doh, et al., 2017).

Tertiary prevention mitigates against adverse effects of ongoing illness or injury. Rehabilitation interventions and support groups are examples of tertiary prevention efforts for chronic health conditions, such as cancer, stroke, and diabetes. Alcoholics Anonymous and other 12-step groups may be considered to be the tertiary prevention interventions, with parallel groups for gambling and even gaming. Relatively few persons access tertiary prevention programs, and those who, by definition, already have experienced significant problems.

Tertiary prevention differs from treatment, which refers to interventions designed to reverse or minimize conditions or diseases, typically in those actively seeking help. As Király et al. (2018) and other reviews (King, Delfabbro, Griffiths, \& Gradisar, 2011; Zajac, Ginley, Chang, \& Petry, 2017) note, evaluations of treatments for IGD have just begun. No pharmacological or psychosocial treatments for IGD have strong evidence of efficacy (King et al., 2011; King, Delfabbro, Wu, et al., 2017; Zajac et al., 2017), and the quality of study designs remains poor. Ideally, treatments as well as tertiary prevention efforts will be guided by physiological as well as psychological data regarding the nature of the condition and its comorbidities and complications.

Eventually, efficacious treatment and primary, secondary, and tertiary prevention strategies may exist for IGD. However, it is unlikely that the gaming industry will (or should) be involved in developing or objectively assessing such efforts. Although they could be mandated to fund them via governmental regulations or taxation strategies, separation of funding and research seems prudent. Decades of experiences with the nicotine, tobacco, and gambling industries should bode against reliance on industry support for research. Industries that benefit directly from the use of products with adverse consequences have inherent conflicts of interest in stimulating efficacious prevention and treatment efforts. We urge policymakers, clinicians, and researchers (including epidemiologists, neuroscientists, public policy experts, etc.) across a range of conditions (including substance use and addictive behaviors, ADHD, other common childhood disorders, and mental health conditions broadly) to lend their expertise to combat gaming problems and IGD in this generation of youth and young adults.

Funding sources: This manuscript was supported by grants R21DA042900, K23DA034879, P50DA09241, and P60AA03510 from the National Institutes of Health (NIH). The content is solely the responsibility of the authors and does not necessarily represent the official views of the NIH.

Authors' contribution: The initial draft of this paper was prepared by NMP. All authors have contributed material to the paper and/or provided comments on it and have approved the final version of the manuscript.

Conflict of interest: No conflicts of interest were reported by any author.

\section{REFERENCES}

American Psychiatric Association. (2013). Diagnostic and statistical manual of mental disorders $\left(D S M-5^{\circledR}\right)$. Washington, DC: American Psychiatric Association.

Carlson, S. A., Fulton, J. E., Lee, S. M., Foley, J. T., Heitzler, C., \& Huhman, M. (2010). Influence of limit-setting and participation in physical activity on youth screen time. Pediatrics, 126(1), e89-e96. doi:10.1542/peds.2009-3374

Desai, R. A., Krishnan-Sarin, S., Cavallo, D., \& Potenza, M. N. (2010). Video-gaming among high school students: Health correlates, gender differences, and problematic gaming. Pediatrics, 126(6), e1414-e1424. doi:10.1542/peds.2009-2706

Du Mouchel, W., Williams, A. F., \& Zador, P. (1987). Raising the alcohol purchase age: Its effects on fatal motor vehicle crashes in twenty-six states. The Journal of Legal Studies, 16(1), 249-266. doi:10.1086/467830

Ennett, S. T., Tobler, N. S., Ringwalt, C. L., \& Flewelling, R. L. (1994). How effective is Drug Abuse Resistance Education? A meta-analysis of Project DARE outcome evaluations. 
American Journal of Public Health, 84(9), 1394-1401. doi:10.2105/AJPH.84.9.1394

Gentile, D. A. (in press). Thinking more broadly about policy responses to problematic video game use: A response to Király et al. (2018). Journal of Behavioral Addictions.

Gentile, D. A., Choo, H., Liau, A., Sim, T., Li, D., Fung, D., \& Khoo, A. (2011). Pathological video game use among youths: A two-year longitudinal study. Pediatrics, 127(2), e319-e329. doi:10.1542/peds.2010-1353

Ginley, M. K., Whelan, J. P., Pfund, R. A., Peter, S. C., \& Meyers, A. W. (2017). Warning messages for electronic gambling machines: Evidence for regulatory policies. Addiction Research \& Theory, 25, 1-10. doi:10.1080/16066359.2017. 1321740

King, D. L., Delfabbro, P. H., Doh, Y. Y., Wu, A. M., Kuss, D. J., Pallesen, S., Mentzoni, R., Carragher, N., \& Sakuma, H. (2017). Policy and prevention approaches for disordered and hazardous gaming and Internet use: An international perspective. Prevention Science, 19(2), 233-249. doi:10.1007/s11121017-0813-1

King, D. L., Delfabbro, P. H., Griffiths, M. D., \& Gradisar, M. (2011). Assessing clinical trials of Internet addiction treatment: A systematic review and CONSORT evaluation. Clinical Psychology Review, 31(7), 1110-1116. doi:10.1016/j.cpr. 2011.06.009

King, D. L., Delfabbro, P. H., Wu, A. M., Doh, Y. Y., Kuss, D. J., Pallesen, S., Mentzoni, R., Carragher, N., \& Sakuma, H. (2017). Treatment of Internet gaming disorder: An international systematic review and CONSORT evaluation. Clinical Psychology Review, 54, 123-133. doi:10.1016/j.cpr.2017. 04.002

Király, O., Griffiths, M. D., King, D. L., Lee, H. K., Lee, S. Y., Bányai, F., Zsila, Á., Takacs, Z. K., \& Demetrovics, Z. (2018). Policy responses to problematic video game use: A systematic review of current measures and future possibilities. Journal of Behavioral Addictions, 1-15. Advance online publication. doi:10.1556/2006.6.2017.050

Király, O., Griffiths, M. D., Urbán, R., Farkas, J., Kökönyei, G., Elekes, Z., Tamás, D., \& Demetrovics, Z. (2014). Problematic Internet use and problematic online gaming are not the same: Findings from a large nationally representative adolescent sample. Cyberpsychology, Behavior, and Social Networking, 17(12), 749-754. doi:10.1089/cyber.2014.0475

Lemmens, J. S., Valkenburg, P. M., \& Peter, J. (2011). Psychosocial causes and consequences of pathological gaming. Computers in Human Behavior, 27(1), 144-152. doi:10.1016/j. chb.2010.07.015

Madras, B. K., Compton, W. M., Avula, D., Stegbauer, T., Stein, J. B., \& Clark, H. W. (2009). Screening, brief interventions, referral to treatment (SBIRT) for illicit drug and alcohol use at multiple healthcare sites: Comparison at intake and 6 months later. Drug and Alcohol Dependence, 99(1), 280-295. doi:10.1016/j.drugalcdep.2008.08.003

Montag, C., Bey, K., Sha, P., Li, M., Chen, Y. F., Liu, W. Y., Zhu, Y. K., Li, C. B., Markett, S., Keiper, J., \& Reuter, M. (2015). Is it meaningful to distinguish between generalized and specific Internet addiction? Evidence from a cross-cultural study from Germany, Sweden, Taiwan and China. Asia-Pacific Psychiatry, 7(1), 20-26. doi:10.1111/appy.12122

Müller, K. W., Janikian, M., Dreier, M., Wölfling, K., Beutel, M. E., Tzavara, C., Richardson, C., \& Tsitsika, A. (2015).
Regular gaming behavior and Internet gaming disorder in European adolescents: Results from a cross-national representative survey of prevalence, predictors, and psychopathological correlates. European Child \& Adolescent Psychiatry, 24(5), 565-574. doi:10.1007/s00787-014-0611-2

Neighbors, C., Rodriguez, L. M., Rinker, D. V., Gonzales, R. G., Agana, M., Tackett, J. L., \& Foster, D. W. (2015). Efficacy of personalized normative feedback as a brief intervention for college student gambling: A randomized controlled trial. Journal of Consulting and Clinical Psychology, 83(3), 500-511. doi:10.1037/a0039125

Petry, N. M., \& O'Brien, C. P. (2013). Internet gaming disorder and the DSM-5. Addiction, 108(7), 1186-1187. doi:10.1111/ add. 12162

Petry, N. M., Rehbein, F., Gentile, D. A., Lemmens, J. S., Rumpf, H. J., Mößle, T., Bischof, G., Tao, R., Fung, D. S., Borges, G., Auriacombe, M., González Ibáñez, A., Tam, P., \& O’Brien, C. P. (2014). An international consensus for assessing Internet gaming disorder using the new DSM-5 approach. Addiction, 109(9), 1399-1406. doi:10.1111/add.12457

Petry, N. M., Rehbein, F., Ko, C. H., \& O’Brien, C. P. (2015). Internet gaming disorder in the DSM-5. Current Psychiatry Reports, 17(9), 72. doi:10.1007/s11920-015-0610-0

Petry, N. M., Stinson, F. S., \& Grant, B. F. (2005). Comorbidity of DSM-IV pathological gambling and other psychiatric disorders: Results from the National Epidemiologic Survey on Alcohol and Related Conditions. The Journal of Clinical Psychiatry, 66(5), 564-574. doi:10.4088/JCP.v66n0504

Petry, N. M., Zajac, K., \& Ginley, M. K. (2018). Behavioral addictions as mental disorders: To be or not to be? Annual Review of Clinical Psychology, 14(1), 399-423. doi:10.1146/ annurev-clinpsy-032816-045120

Rehbein, F., \& Baier, D. (2013). Family-, media-, and schoolrelated risk factors of video game addiction. Journal of Media Psychology, 25(3), 118-128. doi:10.1027/1864-1105/a000093

Rehbein, F., Kliem, S., Baier, D., Mößle, T., \& Petry, N. M. (2015). Prevalence of Internet gaming disorder in German adolescents: Diagnostic contribution of the nine DSM-5 criteria in a state-wide representative sample. Addiction, 110(5), 842-851. doi:10.1111/add.12849

Rehbein, F., \& Mößle, T. (2013). Video game and Internet addiction: Is there a need for differentiation? Sucht, 59(3), 129-142. doi:10.1024/0939-5911.a000245

Rothmund, T., Klimmt, C., \& Gollwitzer, M. (2016). Low temporal stability of excessive video game use in German adolescents. Journal of Media Psychology, 30(2), 53-65. doi:10.1027/1864-1105/a000177

Scharkow, M., Festl, R., \& Quandt, T. (2014). Longitudinal patterns of problematic computer game use among adolescents and adults - A 2-year panel study. Addiction, 109(11), 1910-1917. doi:10.1111/add.12662

Siomos, K. E., Dafouli, E. D., Braimiotis, D. A., Mouzas, O. D., \& Angelopoulos, N. V. (2008). Internet addiction among Greek adolescent students. CyberPsychology \& Behavior, 11(6), 653-657. doi:10.1089/cpb.2008.0088

Thege, B. K., Woodin, E. M., Hodgins, D. C., \& Williams, R. J. (2015). Natural course of behavioral addictions: A 5-year longitudinal study. BMC Psychiatry, 15(1), 4-18. doi:10.1186/ s12888-015-0383-3

Toumbourou, J. W., Stockwell, T., Neighbors, C., Marlatt, G. A., Sturge, J., \& Rehm, J. (2007). Interventions to reduce harm 
associated with adolescent substance use. The Lancet, 369(9570), 1391-1401. doi:10.1016/S0140-6736(07)60369-9

US Department of Health and Human Services. (2016). Facing addiction in America: The Surgeon General's Report on alcohol, drugs, and health (HHS Publication No. SMA 16-4991). Washington, DC: US Government Printing Office. van Rooij, A. J., Kuss, D. J., Griffiths, M. D., Shorter, G. W., Schoenmakers, M. T., \& van De Mheen, D. (2014). The (co-)occurrence of problematic video gaming, substance use, and psychosocial problems in adolescents. Journal of Behavioral Addictions, 3(3), 157-165. doi:10.1556/JBA.3. 2014.013

van Rooij, A. J., Schoenmakers, T. M., van de Eijnden, R. J., \& van de Mheen, D. (2010). Compulsive Internet use: The role of online gaming and other Internet applications. Journal of Adolescent Health, 47(1), 51-57. doi:10.1016/j.jadohealth. 2009.12.021

van Rooij, A. J., Schoenmakers, T. M., Vermulst, A. A., van den Eijnden, R. J., \& van de Mheen, D. (2011). Online video game addiction: Identification of addicted adolescent gamers.
Addiction, 106(1), 205-212. doi:10.1111/j.1360-0443.2010. 03104.x

Welte, J. W., Barnes, G. M., Tidwell, M. C. O., \& Hoffman, J. H. (2011). Gambling and problem gambling across the lifespan. Journal of Gambling Studies, 27(1), 49-61. doi:10.1007/ s10899-010-9195-z

Williams, A. F., \& Lund, A. K. (1986). Seat belt use laws and occupant crash protection in the United States. American Journal of Public Health, 76(12), 1438-1442. doi:10.2105/ AJPH.76.12.1438

Wittek, C. T., Finserås, T. R., Pallesen, S., Mentzoni, R. A., Hanss, D., Griffiths, M. D., \& Molde, H. (2016). Prevalence and predictors of video game addiction: A study based on a national representative sample of gamers. International Journal of Mental Health and Addiction, 14(5), 672-686. doi:10.1007/ s11469-015-9592-8

Zajac, K., Ginley, M. K., Chang, R., \& Petry, N. M. (2017). Treatments for Internet gaming disorder and Internet addiction: A systematic review. Psychology of Addictive Behaviors, 31(8), 979-994. doi:10.1037/adb0000315 